\title{
Statistics for the Rest of Us
}

\section{CONSORT and beyond}

\author{
Eugene H. Blackstone, MD
}

See related articles on pages

233, 241, 243, 245, 247, and 249.

From the Department of Thoracic and Cardiovascular Surgery, Cleveland Clinic, Cleveland, Ohio.

Received for publication March 1, 2006; accepted for publication March 3, 2006.

Address for reprints: Eugene H. Blackstone, MD, Department of Thoracic and Cardiovascular Surgery, Cleveland Clinic, 9500 Euclid Ave/JJ40, Cleveland, OH 44195 (E-mail: blackse@ccf.org).

J Thorac Cardiovasc Surg 2006;132:229-32

$0022-5223 / \$ 32.00$

Copyright (C) 2006 by The American Association for Thoracic Surgery

doi:10.1016/j.jtcvs.2006.03.040

\section{CONSORT}

Napoleon's march on Moscow commenced on June 23, 1812, as the Grande Armée of 691,500 men, the largest army assembled in European history, crossed the Neman River. Attrition during its advance and ignominious winter retreat, to 22,000 men on December 14, 1812, when it recrossed the river, was depicted by Charles Joseph Minard in what many consider the best statistical graphic ever produced (Figure 1). Less spectacular, but terribly informative, was the depiction along similar lines of patients screened for entry into the Coronary Artery Surgery Study (CASS) at 11 randomizing sites, dwindling from 16,626 to 780 randomized patients (Figure 2). ${ }^{1}$

In the mid-1990s, an international group of journal editors, statisticians, and clinical trialists sought to improve the quality of reporting randomized controlled trials (RCTs). They devised the CONSORT (Consolidated Standards of Reporting Trials) statement, checklist, and flowchart ${ }^{1,2}$ for reporting RCTs that had at its core a complete accounting for cases, from screening through final analysis. Although not as dramatic and artistic as either the Minard or CASS trial graph, the CASS trial CONSORT flowchart is highly informative and even reveals holes in the report (Figure 3).

Biomedical journals, including the Journal of Thoracic and Cardiovascular Surgery, were asked to adopt CONSORT and to require authors to comply with its reporting standards, not just follow a set of recommendations, guidelines, or suggestions. Not wishing to be prescriptive, this journal included CONSORT as recommendations in "Instructions to Statisticians" (then a separate document from "Instructions to Authors"). This separate set of instructions, however, was subsequently dispensed with, and with it, CONSORT.

Tiruvoipati and colleagues ${ }^{3}$ in this issue have taken cardiothoracic journals to task for publishing RCTs that do not comply with CONSORT and for not officially subscribing to it. They document why suboptimal reporting is a handicap both to full understanding of a trial and to its future use in high-quality meta-analyses. By implication, they also believe that not using the CONSORT flowchart and checklist from the very outset of a trial can decrease its quality. We challenged the authors to use data they had gathered to look at a compliancestudy quality correlation, but they declined the opportunity. After all, we reasoned, if quality of the trial is not improved by CONSORT, why force authors to go through a standardized reporting process only for receiving a higher score on someone else's meta-analysis quality scale?

However, careful study of the CONSORT documents will convince anyone involved in either RCTs or observational clinical research that the flowchart and checklist capture exactly the information that is needed for good science. Indeed, if used from the outset in planning a study, it keeps ever before the investigator things that might otherwise be forgotten or be reinvented study by study. Thus, we view CONSORT as an excellent starting point for a well- 


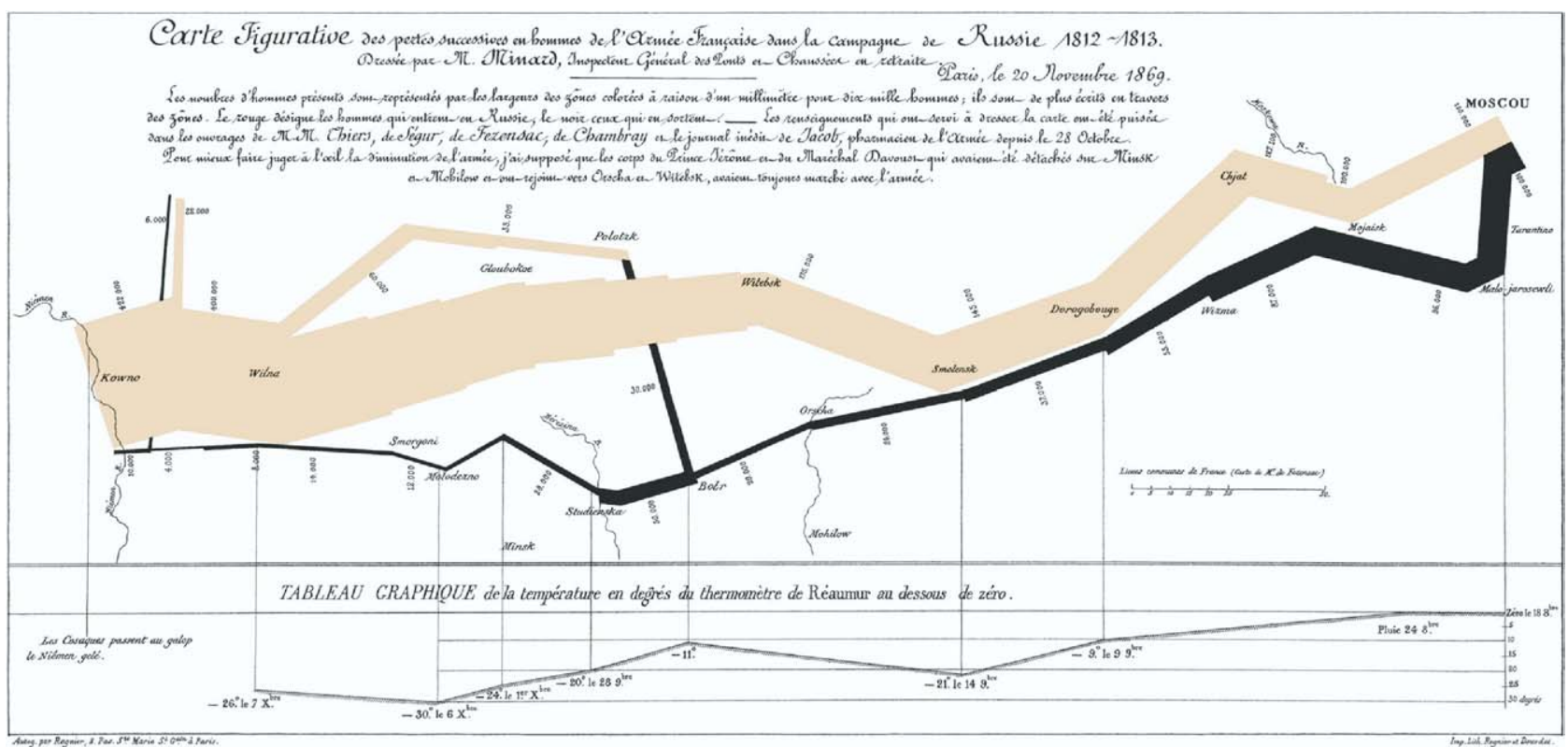

Figure 1. Charles Joseph Minard's multifactorial statistical map showing the advance (yellow band) of Napoleon's army from the Russian-Polish border to Moscow and its retreat (black band). The width of the band is proportional to the size of the remaining army. Along the bottom of the graph is the temperature-time scale during the winter retreat. Reprinted from Edward R. Tufte, The Visual Display of Quantitative Information, Graphics Press, Second Edition, 2001, by permission of the publisher.

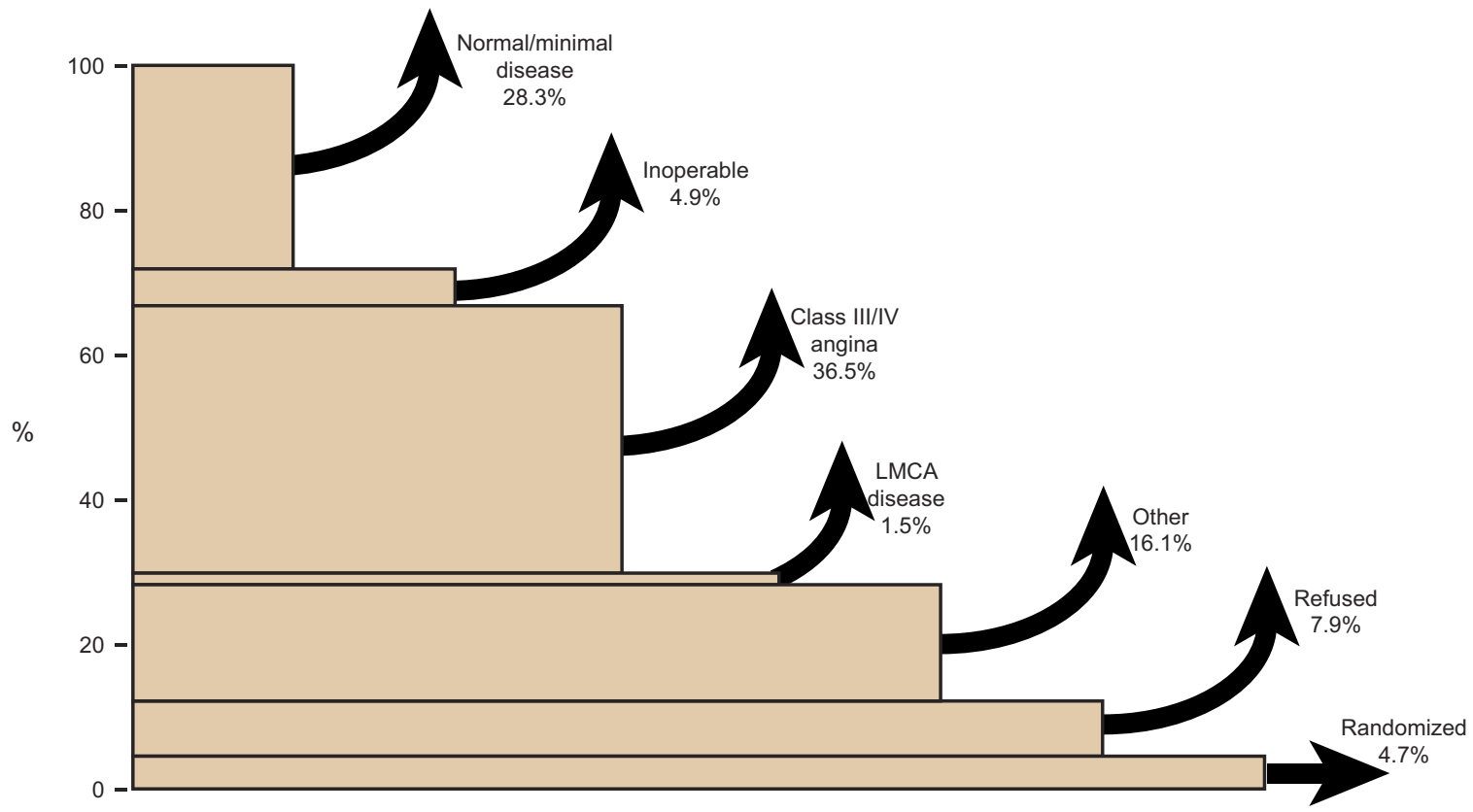

Figure 2. Depiction of the Coronary Artery Surgery Study population, from initial screening of 16,626 patients to a final randomized group of $\mathbf{7 8 0}$. Adapted from Figure 1 from the report of the Coronary Artery Surgery Study. ${ }^{1}$ 


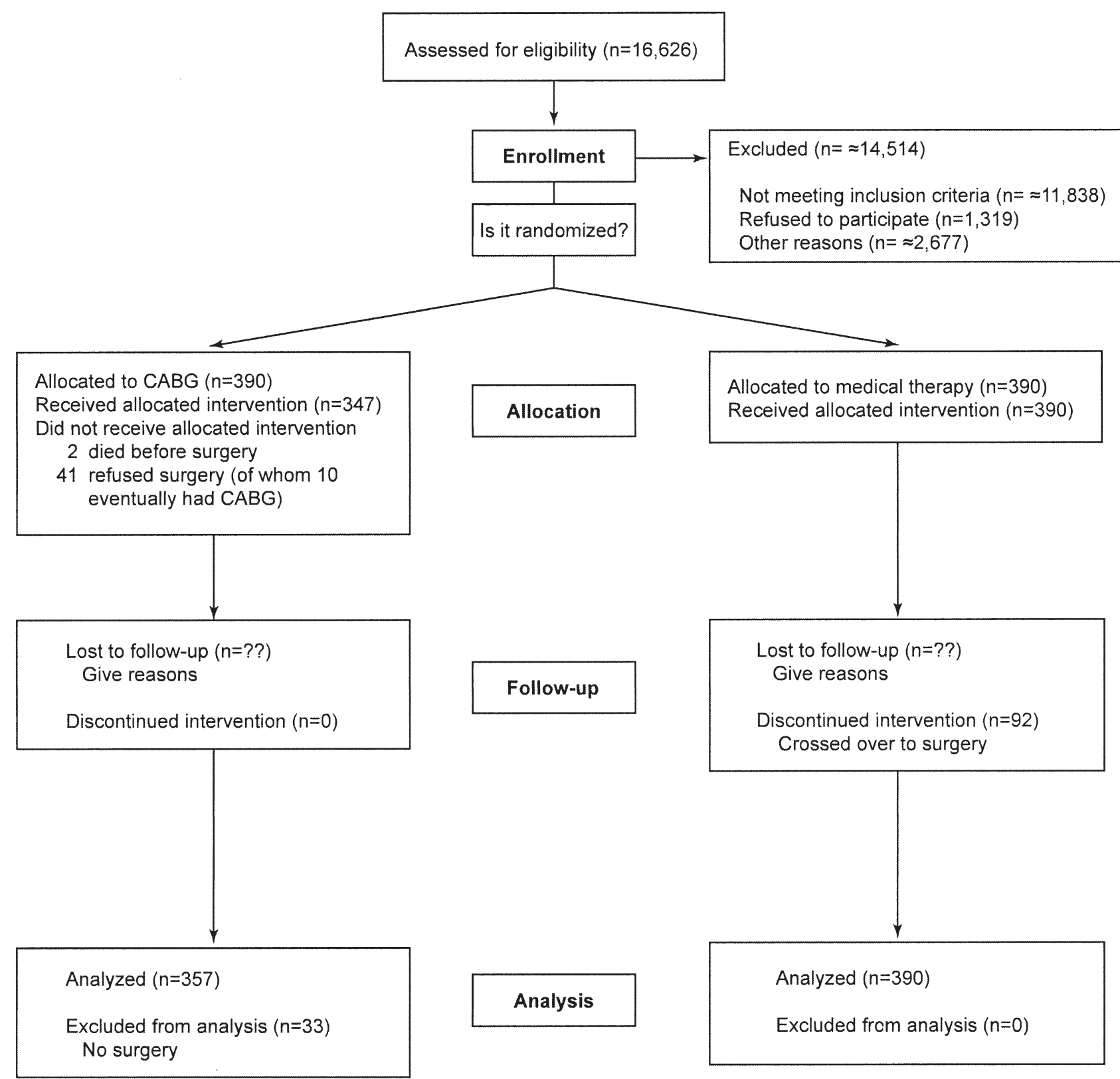

Figure 3. Depiction of the Coronary Artery Surgery Study (CASS) population in CONSORT flowchart format.

conceived clinical study of any kind rather then just another hoop to jump through to get an article into publication.

Thus, the editors of this journal have reviewed CONSORT and recommended that the following statement be added to "Instructions for Authors":

Manuscripts reporting the results of randomized controlled trials (RCTs) should include the CONSORT flow diagram showing the progress of patients throughout the trial. ${ }^{4}$ The CONSORT check- list also should be completed and submitted with the manuscript.

\section{Beyond CONSORT}

When we received the manuscript from Tiruvoipati and colleagues, ${ }^{3}$ we also believed that it could catalyze a useful and serious discussion of some important issues that RCTs raise in surgery. Our bias is that there are not enough cardiothoracic surgical RCTs. However, we recognize that there are limited funding sources for such studies, unlike 
drug trials. Furthermore, surgery is not a uniform standardized dose like a pill but is always confounded by the skill of the surgeon. Randomized trials also go against one of the fundamental things surgeons do: select an appropriate operation for the appropriate patient. We call this "indication" not "bias." RCTs seek to erase selection "bias."

To air these and other RCT issues of interest to surgeons, we have asked the reviewers of the article by Tiruvoipati and colleagues ${ }^{3}$ to write brief commentaries dealing either with issues raised by the article or with RCTs in general. These individuals are a diverse group: a cardiologist and contributing editor of the Journal of the American Medical Association; a surgeon-mathematician and head of the Coordinating Center for the National Emphysema Treatment Trial, who has written one of the definitive texts on clinical trials $^{5}$; a cardiac surgeon-ethicist; and a neurosurgeon who has led many important surgical RCTs and is the founding editor in chief of the Annals of Surgical Oncology and CEO of the American Society of Clinical Oncology.

\section{References}

1. Coronary Artery Surgery Study (CASS): a randomized trial of coronary artery bypass surgery. Survival data. Circulation. 1983;68:939-50.

2. Moher D, Schulz KF, Altman D. The CONSORT statement: revised recommendations for improving the quality of reports of parallel-group randomized trials. JAMA. 2001;285:1987-91.

3. Tiruvoipati R, Balasubramanian SP, Atturu G, Peek GJ, Elbourne D. Improving the quality of reporting randomized controlled trials in cardiothoracic surgery: the way forward. J Thorac Cardiovasc Surg. 2006;132:233-40.

4. Available at http://www.consort-statement.org

5. Piantadosi S. Clinical trials: a methodologic perspective. New York: John Wiley \& Sons; 1997.

\section{Interactive eLearning Activities \\ http://learning.ctsnet.org}

The Joint Council on Thoracic Surgery Education was pleased to introduce a series of unique eLearning activities to CTSNet users at the AATS annual meeting in Philadelphia. Sponsored by several cardiothoracic surgical groups, this exciting new educational tool contains narrated videos of actual surgical procedures followed by a series of questions and an evaluation to earn Continuing Medical Education credit.

* Diagnosis and Management of Complications of Mitral Valve Repair

* Off Pump Coronary Artery Bypass

* OPCAB Debriefing

* Pediatric Cardiopulmonary Bypass Emergency Situations

\section{Experience these new educational tools today and provide us with your feedback. Go to: http://learning.ctsnet.org}

William E. Baumgartner, Chair

Joint Council on Thoracic Surgery Education

Sponsored By:

American Association for Thoracic Surgery

The Society of Thoracic Surgeons

European Association for Cardio-Thoracic Surgery

Children's Memorial Hospital 